Kong. Res. J. 1(2): 31-34, 2014

Kongunadu Arts and Science College, Coimbatore

\title{
SLIGHTLY *g-CONTINUOUS FUNCTIONS
}

Devi, $R^{*}$. and $M$. Vigneshwaran

Department of Mathematics, Kongunadu Arts and Science College (Autonomous), Coimbatore - 641029 ,

*Email:rdevicbe@yahoo.com

\begin{abstract}
In this paper we introduce slightly *g $\alpha$-contoinuos function and investigated the properties of slightly ${ }^{*} \mathrm{~g} \alpha$-continous functions. By utilizing ${ }^{*} \mathrm{~g} \alpha$-open sets, we derived the theorem deals with covering properties and axioms.
\end{abstract}

Keywords: *g $\alpha$-closed sets, ${ }^{*}$ g $\alpha$-open sets, slightly ${ }^{*}$ g $\alpha$-continuous, ${ }^{*}$ g $\alpha$-regular, ${ }^{*}$ g $\alpha$-normal , AMS Subject classification 54C10, 54C08, 54C05.

\section{INTRODUCTION AND PRELIMINARIES}

Continuous functions play an important role in the field of Mathematics. Large number of continuous functions have been introduced and their properties were investigated over the last two decades. Some of them are strongly $\alpha$-irresoluteness (Fao, 1987) $\alpha$-irresoluteness (Mashhour, et al., 1983), $\alpha$-continuity (Mashhour, 1983; Njastad, 1965), pre-continuity (Blumberg, 1992; Mashhour, 1982),semi-continuity (Levine, 1963), $\gamma$-continuity (El-Atik, 1997), slightly continuity (Jain, 1980; Singal and Jain, 1997)] and slightly $\gamma$-continuity (Eradal Ekici and Miguel Caldas, 2004).

The aim of this paper is to introduce slightly ${ }^{*}$ g $\alpha$-continuous functions and investigate the properties of slightly ${ }^{*} \mathrm{~g} \alpha$-continuous functions. By utilizing *g $\alpha$-open sets, we derive the theorems which deals with covering properties and separation axioms.

Throughout the present paper, $\mathrm{X}$ and $\mathrm{Y}$ are always topological spaces. Let A be a subspace of X. We denote the interior and closure of a set $A$ by $\operatorname{int}(\mathrm{A})$ and $\operatorname{cl}(\mathrm{A})$, respectively.

\subsection{Definition}

A subset $A$ of a space $X$ is said to be $\alpha$-open if $A \subset \operatorname{int}(\operatorname{cl}(\operatorname{int}(A))) \quad$ (Mashhour, 1983). The complement of $\alpha$-open set is closed.

\subsection{Definition}

The intersection of all $\alpha$-closed sets of $X$ containing $\mathrm{A}$ is called the $\alpha$-closure of $\mathrm{A}$ and is denoted by $\alpha \mathrm{cl}(\mathrm{A})$.

\subsection{Definition}

A subset $A$ of a space $X$ is called
1. g $\alpha$-closed (Maki et al., 1993) if $\alpha \operatorname{cl}(\mathrm{A}) \subseteq \mathrm{U}$ whenever $\mathrm{A} \subseteq \mathrm{U}$ and $\mathrm{U}$ is $\alpha$-open and the complement of $\mathrm{g} \alpha$ closed set is g $\alpha$-open.

2. ${ }^{*}$ g $\alpha$-closed (Devi and Vigneshwaran, 2007) if

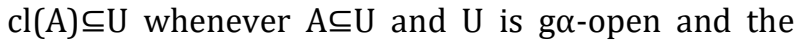
complement of * $\mathrm{g} \alpha$-closed set is * $\mathrm{g} \alpha$-open.

\subsection{Definition}

A function $f:(X, \tau) \rightarrow(Y, \sigma)$ is called of (4) * $\mathrm{g} \alpha-$ continuous of[2] if $\mathrm{f}^{-1}(\mathrm{~V})$ is ${ }^{*} \mathrm{~g} \alpha$-closed in $(\mathrm{x}, \tau)$ for every closed set $\mathrm{V}$ of $(\mathrm{Y}, \sigma)$.

The family of all ${ }^{*} \mathrm{~g} \alpha$-open (resp. ${ }^{*} \mathrm{~g} \alpha$-clopen and clopen) sets of $\mathrm{X}$ is denoted ${ }^{*} \mathrm{~g} \alpha \mathrm{O}(\mathrm{X})$ (resp. ${ }^{*} \mathrm{~g} \alpha \mathrm{CO}(\mathrm{X})$ and $\operatorname{CO}(\mathrm{X})$.

\section{SLIGHTLY *GA-CONTINUOUS FUNCTIONS}

\subsection{Definition}

A function $\mathrm{f}:(\mathrm{X}, \tau) \rightarrow(\mathrm{Y}, \sigma)$ is called

1. Slighly ${ }^{*} \mathrm{~g} \alpha$-continuous at a point $\mathrm{x} \in \mathrm{X}$ if for each clopen subset $\mathrm{V}$ in $\mathrm{Y}$ containing $\mathrm{f}(\mathrm{x})$, there exists a *g $\alpha$-open subset $\mathrm{U}$ in $\mathrm{X}$ containing $\mathrm{x}$ such that $\mathrm{f}(\mathrm{U}) \subset \mathrm{V}$.

2. Slightly * $\alpha \alpha$-continuous if it has this property at each point of $X$.

\subsection{Theorem}

Let $(X, \tau)$ and $(Y, \sigma)$ be topological spaces. The following statements are equivalent for a function $\mathrm{f}$ : $(\mathrm{X}, \tau) \rightarrow(\mathrm{Y}, \sigma):$

\section{1. f is slightly ${ }^{*} \mathrm{~g} \alpha$-continuous.}

2. for every clopen set $\mathrm{V} \subset \mathrm{Y}, \mathrm{f}^{-1}(\mathrm{~V})$ is ${ }^{*} \mathrm{~g} \alpha$-open.

3. for every clopen set $\mathrm{V} \subset Y, \mathrm{f}^{-1}(\mathrm{~V})$ is ${ }^{*} \mathrm{~g} \alpha$-closed.

4. for every clopen set $\mathrm{V} \subset Y, \mathrm{f}^{-1}(\mathrm{~V})$ is ${ }^{*} \mathrm{~g} \alpha$-clopen. 
$\operatorname{Proof}(1) \Rightarrow(2)$ : Let $\mathrm{V}$ be a clopen subset of $\mathrm{Y}$ and let. Since $f(x) \in V$ by(1), there exists a *g $\alpha$-open set $U_{x}$ in $X$ containing $x$ such that $U_{x} \subset f^{-1}(V)$. We obtain $f^{-}$ ${ }^{1}(\mathrm{~V})=\mathrm{U} \mathrm{x} \in \mathrm{f}^{-1}(\mathrm{~V}) \mathrm{U}_{\mathrm{x}}$. Thus $\mathrm{f}^{-1}(\mathrm{~V})$ is ${ }^{*} \mathrm{~g} \alpha$-open.

$(2) \Rightarrow(3)$ : Let $V$ be a clopen subset of $Y$. Then $Y \backslash V$ is clopen. By (2) $f^{-1}(Y \backslash V)=X \backslash f^{-1}(V)$ is *g $\alpha$-open $f^{-1}(V)$ is *g $\alpha$-closed.

(3) $\Rightarrow(4)$ : Obivious.

$(4) \Rightarrow(1)$ : Let $V$ be a clopen subset in $Y$ containing $\mathrm{f}(\mathrm{x})$. By $(4), \mathrm{f}^{-1}(\mathrm{~V})$ is ${ }^{*} \mathrm{~g} \alpha$-clopen. Take $\mathrm{U}=\mathrm{f}^{-1}(\mathrm{~V})$. Then $\mathrm{f}(\mathrm{U}) \subset \mathrm{V}$. Hence $\mathrm{f}$ is slightly ${ }^{*} \mathrm{~g} \alpha$-continuous.

\subsection{Theorem}

If $\mathrm{f:}(\mathrm{X}, \tau) \rightarrow(\mathrm{Y}, \sigma)$ is slightly ${ }^{*} \mathrm{~g} \alpha$-continuous and $A \in \tau$, then $\mathrm{f} \backslash \mathrm{A}: \mathrm{A} \rightarrow \mathrm{Y}$ is slightly ${ }^{*} \mathrm{~g} \alpha$-continuous.

Proof. Let $V$ be a clopen subset of Y. We have $(f \backslash A)$ ${ }^{1}(V)=f^{-1}(V) \cap A$. Since $f^{-1}(V)$ is ${ }^{*} g \alpha$-open and $A$ is open, then $(f \backslash A)^{-1}(V)$ is ${ }^{*} g \alpha$-open in the relative topology of $A$. Thus $\backslash A$ is slightly ${ }^{*} g \alpha$-continuous.

\subsection{Theorem}

Let $f: X \rightarrow Y$ be a function and let $g: X \rightarrow X x Y$ be the graph function of $f$, defined by $g(x)=(x, f(x))$ for every $\mathrm{x} \in \mathrm{X}$. Then $\mathrm{g}$ is slightly ${ }^{*} \mathrm{~g} \alpha$-continuous if and only if $\mathrm{f}$ is slightly ${ }^{*} \mathrm{~g} \alpha$-continuous.

Proof. Let $\mathrm{V} \epsilon \mathrm{CO}(\mathrm{Y})$, then $\mathrm{XxV} \in \mathrm{CO}(\mathrm{XxY})$. Since $\mathrm{g}$ is slightly $* g \alpha$-continuous then $\mathrm{f}^{-1}(\mathrm{~V})=\mathrm{g}$ ${ }^{1}(\mathrm{XxV}) \epsilon^{*} \mathrm{~g} \alpha \mathrm{O}(\mathrm{X})$. Thus $\mathrm{f}$ is slightly ${ }^{*} \mathrm{~g} \alpha$-continuous.

Conversely, let $\mathrm{x} \in \mathrm{X}$ and let $\mathrm{W}$ be a closed of $\mathrm{XxY}$ containing $\mathrm{g}(\mathrm{x})$. Then $\mathrm{W} \cap(\{\mathrm{x}\} \mathrm{xY})$ is clopen in $\{\mathrm{x}\} \mathrm{xY}$ containing $\mathrm{g}(\mathrm{x})$. Also $\{\mathrm{x}\} \mathrm{xY}$ is homeomorphic to $\mathrm{Y}$. Hence $\{\mathrm{y} \epsilon \mathrm{Y} \backslash(\mathrm{x}, \mathrm{y}) \in \mathrm{W}\}$ is clopen subset of $\mathrm{Y}$. Since $\mathrm{f}$ is * $\mathrm{g} \alpha$-continuous, $\mathrm{U}\left\{\mathrm{f}^{-1}(\mathrm{y}) \mid(\mathrm{x}, \mathrm{y}) \in \mathrm{W}\right\}$ is ${ }^{*} \mathrm{~g} \alpha$-open subset of $\mathrm{X}$. Then $\mathrm{x} \epsilon \mathrm{U}\left\{\mathrm{f}^{-1}(\mathrm{y}) \mid(\mathrm{x}, \mathrm{y}) \in \mathrm{W}\right\} \subset \mathrm{g}^{-1}(\mathrm{~W})$. Hence $\mathrm{g}^{-1}(\mathrm{~W})$ is ${ }^{*} \mathrm{~g} \alpha$-open. Then $\mathrm{g}$ is slightly ${ }^{*} \mathrm{~g} \alpha$ continuous.

\subsection{Definition}

\section{A function $\mathrm{f}: \mathrm{X} \rightarrow \mathrm{Y}$ is called}

1. ${ }^{*} \mathrm{~g} \alpha$-irresolute if for every ${ }^{*} \mathrm{~g} \alpha$-open subset $\mathrm{A}$ of $\mathrm{Y}, \mathrm{f}$ $1(\mathrm{~A})$ is * $\mathrm{g} \alpha$-open in $\mathrm{Y}$.

2. ${ }^{*} \mathrm{~g} \alpha$-open if for every ${ }^{*} \mathrm{~g} \alpha$-open subset $\mathrm{A}$ of $\mathrm{X}, \mathrm{f}(\mathrm{A})$ is *go-open in Y.

\subsection{Theorem}

Let $\mathrm{f}: \mathrm{X} \rightarrow \mathrm{Y}$ and $\mathrm{g}: \mathrm{Y} \rightarrow \mathrm{Z}$ be functions. Then, the following properties hold:

1. If $\mathrm{f}$ is ${ }^{*} \mathrm{~g} \alpha$-irresolute and $\mathrm{g}$ is slightly ${ }^{*} \mathrm{~g} \alpha$ continuous, then gof: $\mathrm{X} \rightarrow \mathrm{Z}$ is slightly ${ }^{*} \mathrm{~g} \alpha$-continuous.

2. If $\mathrm{f}$ is ${ }^{*} \mathrm{~g} \alpha$-irresolute and $\mathrm{g}$ is slightly ${ }^{*} \mathrm{~g} \alpha$ continuous, then gof: $\mathrm{X} \rightarrow \mathrm{Z}$ is slightly ${ }^{*} \mathrm{~g} \alpha$-continuous.
3. If $\mathrm{f}$ is ${ }^{*} \mathrm{~g} \alpha$-irresolute and $\mathrm{g}$ is slightly g-continuous, then gof: $\mathrm{X} \rightarrow \mathrm{Z}$ is slightly ${ }^{*} \mathrm{~g} \alpha$-continuous.

Proof.

(1): Let V be any clopen set in Z. Since g is slightly ${ }^{*}$ g $\alpha$-continuous, then $\mathrm{g}^{-1}(\mathrm{~V})$ is ${ }^{*} \mathrm{~g} \alpha$-open in Y. Since $\mathrm{f}$ is ${ }^{*} \mathrm{~g} \alpha$-irresolute then $\mathrm{f}^{-1}\left(\mathrm{~g}^{-1}(\mathrm{~V})\right)$ is ${ }^{*} \mathrm{~g} \alpha$-open in $\mathrm{X}$. Therefore gof is slightly ${ }^{*} \mathrm{~g} \alpha$-continuous.

(3): Let V be a clopen set in Z. Since $\mathrm{g}$ is continuous, then $\mathrm{g}^{-1}(\mathrm{~V})$ is open in Y. Implies $\mathrm{g}^{-1}(\mathrm{~V})$ is ${ }^{*} \mathrm{~g} \alpha$-open in Y. Since $\mathrm{f}$ is ${ }^{*} \mathrm{~g} \alpha$-irresolute then $\mathrm{f}^{-1}\left(\mathrm{~g}^{-1}(\mathrm{~V})\right)$ is ${ }^{*} \mathrm{~g} \alpha$-open in $\mathrm{X}$. Therefore gof is slightly ${ }^{*} \mathrm{~g} \alpha$-continuous.

\subsection{Theorem}

Let $\mathrm{f}: \mathrm{X} \rightarrow \mathrm{Y}$ and $\mathrm{g}: \mathrm{Y} \rightarrow \mathrm{Z}$ be functions. If $\mathrm{f}$ is

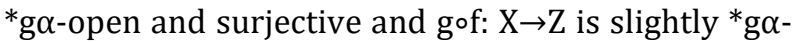
continuous.

Proof. Let $\mathrm{V}$ be any clopen set in Z. Since gof is slightly *ga-continuous, $\quad(g \circ f)^{-1}(V)=f^{-1}(g-$ $\left.{ }^{1}(\mathrm{~V})\right)$ is ${ }^{*} \mathrm{~g} \alpha$-open in $\mathrm{X}$. Since $\mathrm{f}$ is* $\mathrm{g} \alpha$-open, then $\mathrm{f}\left(\mathrm{f}^{-1}(\mathrm{~g}-\right.$ $\left.\left.{ }^{1}(\mathrm{~V})\right)\right)=\mathrm{g}^{-1}(\mathrm{~V})$ is is ${ }^{*} \mathrm{~g} \alpha$-open in Y. Hence $\mathrm{g}$ is slightly *g $\alpha$-continuous.

Combine the above two theorems, we get the following theorem.

\subsection{Theorem.}

Let $\mathrm{f}: \mathrm{X} \rightarrow \mathrm{Y}$ be surjective, ${ }^{*} \mathrm{~g} \alpha$-irresolute and

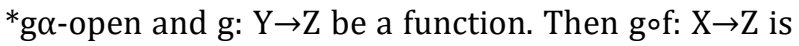

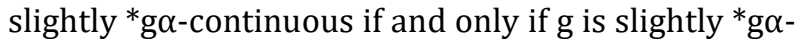
continuous.

\subsection{Definition}

1. A filter base $\Lambda$ is said to be ${ }^{*} \mathrm{~g} \alpha$-convergent to a point $\mathrm{x}$ in $\mathrm{X}$ if for any $\mathrm{U} \in^{*} \mathrm{~g} \alpha \mathrm{O}(\mathrm{X})$ containing $\mathrm{x}$, there exists a $B \in \Lambda$ such that $B \subset U$.

2. A filter base $\Lambda$ is said to be co-convergent to a point $\mathrm{x}$ in $\mathrm{X}$ if for any $\mathrm{U} \in \mathrm{CO}(\mathrm{X})$ containing $\mathrm{x}$, there exists a $B \in \Lambda$ such that $B \subset U$.

\subsection{Theorem}

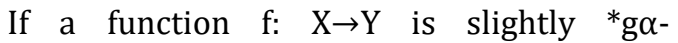
continuous then for each point $\mathrm{x} \in \mathrm{X}$ and each filter base $\Lambda$ in $\mathrm{X}^{*} \mathrm{~g} \alpha$-converging to $\mathrm{x}$, the filter base $\mathrm{f}(\Lambda)$ is co-convergent to $\mathrm{f}(\mathrm{x})$.

Proof. Let $\mathrm{x} \in \mathrm{X}$ and $\Lambda$ be any filter base in $\Lambda$ in $\mathrm{X}^{*} \mathrm{~g} \alpha$ converging to $\mathrm{x}$. Since $\mathrm{f}$ is slightly ${ }^{*} \mathrm{~g} \alpha$-continuous, then for any $\mathrm{V} \in \mathrm{CO}(\mathrm{Y})$ containing $\mathrm{f}(\mathrm{x})$, there exixts a $\mathrm{U} \epsilon^{*} \mathrm{~g} \alpha \mathrm{O}(\mathrm{X})$ containing $\mathrm{x}$ such that $\mathrm{f}(\mathrm{U}) \subset \mathrm{V}$. Since $\Lambda$ is ${ }^{*}$ g $\alpha$-converging to $\mathrm{x}$, there exists a $\mathrm{B} \in \Lambda$ such that $B \subset U$. This means that $\mathrm{f}(\mathrm{B}) \subset \mathrm{V}$ and therefore that filter base $f(\Lambda)$ is co-convergent to $f(x)$. 
2.11. Definition (Devi and Vigneshwaran, 2007)

A space $\mathrm{X}$ is called ${ }^{*} \mathrm{~g} \alpha$-connected provided that $\mathrm{X}$ is not the union of two disjoint non-empty *ga-open sets.

2.12. Theore.

If $\mathrm{f}: \mathrm{X} \rightarrow \mathrm{Y}$ is slightly ${ }^{*} \mathrm{~g} \alpha$-continuous surjective function and $\mathrm{X}$ is ${ }^{*} \mathrm{~g} \alpha$-connected space, then $\mathrm{Y}$ is connected space.

Proof. Suppose that $\mathrm{Y}$ is not connected space. Then there exists non-empty disjoint open sets $U$ and $V$ such that $Y=U U V$. Therefore, $U$ and $V$ are clopen sets in Y. Since $\mathrm{f}$ is slightly ${ }^{*} \mathrm{~g} \alpha$-continuous, then $\mathrm{f}^{-1}(\mathrm{U})$ and $\mathrm{f}^{-1}(\mathrm{~V})$ are ${ }^{*} \mathrm{~g} \alpha$-closed and ${ }^{*} \mathrm{~g} \alpha$-open in X. Moreover, $\mathrm{f}^{-}$ ${ }^{1}(\mathrm{U})$ and $\mathrm{f}^{-1}(\mathrm{~V})$ are non-empty disjoint and $\mathrm{X}=\mathrm{f}^{-}$ ${ }^{1}(\mathrm{U}) \mathrm{U} \mathrm{f}^{-1}(\mathrm{~V})$. This shows that $\mathrm{X}$ is not ${ }^{*} \mathrm{~g} \alpha$-connected. This is a contradiction. Hence $\mathrm{Y}$ is connected.

\section{COVERING PROPERTIES}

\subsection{Definiition}

1. A space $X$ is said to be mildly compact (Stannum, 1974) if every clopen cover of $X$ has a finite subcover.

2. A space $X$ is said to be ${ }^{*}$ g $\alpha$-compact (Devi and Vigneshwaran, 2007) if every ${ }^{*}$ g $\alpha$-open cover has a finite subcover.

3. A subset $A$ of a space $X$ is said to be mildly compact relative to $\mathrm{X}$ if every cover of $\mathrm{A}$ by clopen sets of $\mathrm{X}$ has a finite subcover.

4. A subset A of a space $X$ is said to be *g $\alpha$-compact relative to $\mathrm{X}$ if every ${ }^{*} \mathrm{~g} \alpha$-open sets of $\mathrm{X}$ has a finite subcover.

5. A subset $A$ of a space $X$ is said to be mildly compact if the subspace $A$ is mildly compact.

6. A subset $A$ of a space $X$ is said to be ${ }^{*}$ g $\alpha$-compact if the subspace $A$ is ${ }^{*} \mathrm{~g} \alpha$-compact.

\subsection{Theorem}

If a function $\mathrm{f}: \mathrm{X} \rightarrow \mathrm{Y}$ is slightly ${ }^{*} \mathrm{~g} \alpha$ continuous and $\mathrm{k}$ is ${ }^{*} \mathrm{~g} \alpha$-compact relative to $\mathrm{X}$, then $\mathrm{f}(\mathrm{K})$ is mildly compact in $\mathrm{Y}$.

Proof. Let $\left\{\mathrm{H}_{\alpha}: \alpha \in I\right\}$ be any cover of $\mathrm{f}(\mathrm{K})$ by clopen sets of the subspace $\mathrm{f}(\mathrm{K})$. For each $\alpha \in I$, there exists a clopen sets $K_{\alpha}$ of $Y$ such that $H_{\alpha}=K_{\alpha} \cap f(K)$. For each $\mathrm{x} \in K$, there exists $\alpha_{\mathrm{x}} \in I$,such that $\mathrm{f}(\mathrm{x}) \in \mathrm{K}_{\alpha \mathrm{x}}$. Since the family $\left\{\mathrm{U}_{\mathrm{x}}: \mathrm{x} \in K\right\}$ is a cover of $\mathrm{K}$ by ${ }^{*} \mathrm{~g} \alpha$-open sets of $\mathrm{K}$, there exists a finite subset $\mathrm{K}_{0}$ of $\mathrm{K}$ such that $\mathrm{K}$ $\subset\left\{\mathrm{U}_{\mathrm{x}}: \mathrm{x} \in K_{0}\right\}$. Therefore, we obtain $\mathrm{f}(\mathrm{K}) \subset \mathrm{U}\left\{\mathrm{f} \mathrm{U}\left(\mathrm{U}_{\mathrm{x}}\right)\right.$ : $\left.\mathrm{x} \in K_{0}\right\}$ which is a subset of $\cup\left\{\mathrm{K}_{\alpha \mathrm{x}}: \mathrm{x} \in K_{0}\right\}$. Thus $\mathrm{f}(\mathrm{K})=U\left\{\mathrm{H}_{\alpha \mathrm{x}}: \mathrm{x} \in K_{0}\right\}$ and hence $\mathrm{f}(\mathrm{K})$ is mildly compact.

\subsection{Corolary}

If $\mathrm{f:} \quad \mathrm{X} \rightarrow \mathrm{Y}$ is slightly ${ }^{*} \mathrm{~g} \alpha$-continuous surjective and $\mathrm{X}$ is ${ }^{*} \mathrm{~g} \alpha$-compact then $\mathrm{Y}$ is mildly compact.

Proof. Similar to the above theorem.

\subsection{Definition A space $\mathrm{X}$ is said to be}

1. mildly countably compact (Stannum, 1974) if every clopen countably cover of $\mathrm{X}$ has a finite subcover.

2. mildly Lindelof (Stannum, 1974) if every cover of $\mathrm{X}$ by clopen sets has a countable subcover.

3. countably *g $\alpha$-compact if every ${ }^{*}$ g $\alpha$-open countably cover of $\mathrm{X}$ has a finite subcover.

4. ${ }^{*} \mathrm{~g} \alpha$-Lindelof if every ${ }^{*} \mathrm{~g} \alpha$-open cover of $\mathrm{X}$ has a countable subcover.

5. ${ }^{*}$ g $\alpha$-closed compact if every ${ }^{*}$ g $\alpha$-closed cover of $\mathrm{X}$ has a finite subcover.

6.Countably *g $\alpha$-closed compact if every countable cover of $\mathrm{X}$ by ${ }^{*} \mathrm{~g} \alpha$-closed sets has a finite subcover.

7. ${ }^{*} \mathrm{~g} \alpha$-closed Lindelof if every cover of $\mathrm{X}$ by ${ }^{*} \mathrm{~g} \alpha-$ closed sets has a countable subcover.

\subsection{Theorem}

Let $\mathrm{f}: \mathrm{X} \rightarrow \mathrm{Y}$ be a slightly ${ }^{*} \mathrm{~g} \alpha$-continuous surjection. Then the following statements hold:

1. if $\mathrm{X}$ is ${ }^{*} \mathrm{~g} \alpha$-Lindelof, then $\mathrm{Y}$ is mildly Lindelof.

2. if $\mathrm{X}$ is countably ${ }^{*} \mathrm{~g} \alpha$-compact, then $\mathrm{Y}$ is mildly countably compact.

Proof

(1) : Let $\left\{\mathrm{V}_{\alpha}: \alpha \in I\right\}$ be any clopn cover of $\mathrm{Y}$. Since $\mathrm{f}$ is slightly ${ }^{*} \mathrm{~g} \alpha$-continuous, then $\left\{\mathrm{f}^{-1}\left(\mathrm{~V}_{\alpha}\right): \alpha \in I\right\}$ is a ${ }^{*} \mathrm{~g} \alpha$ open cover of $\mathrm{X}$. Since $\mathrm{X}$ is ${ }^{*} \mathrm{~g} \alpha$-Lindelof, there exists a countable subset $\mathrm{I}_{0}$ of I such that $\mathrm{X}=\mathrm{U}\left\{\mathrm{f}^{-1}\left(\mathrm{~V}_{\alpha}\right): \alpha \in \mathrm{I}_{0}\right\}$. Thus we have $Y=U\left\{V_{\alpha}: \alpha \in I_{0}\right\}$ and $Y$ is mildly Lindelof.

(2) : Similar to (1).

\subsection{Theorem}

Let $\mathrm{f}: \mathrm{X} \rightarrow \mathrm{Y}$ be a slightly ${ }^{*} \mathrm{~g} \alpha$-continuous surjection. Then the following statements hold:

1.if $\mathrm{X}$ is ${ }^{*} \mathrm{~g} \alpha$-closed compact, then $\mathrm{Y}$ is mildly compact 2.if $\mathrm{X}$ is ${ }^{*} \mathrm{~g} \alpha$-closed Lindelof, then $\mathrm{Y}$ is mildly compact Proof. Similar of the above theorem.

\section{REFERENCES}

Devi, R. and M. Vigneshwaran, (2007), On *g $\alpha-$ compact and ${ }^{*}$ go-connected spaces (Submitted). 
Devi, R. and M. Vigneshwaran, (2007) On GaO-kernel in the digital plane (Submitted).

El-Atik, A.A. (1997). A study of some types of mappings on topological spaces, master's thesis, Faculty of science, Tanta University, Tanta, Egypt,

Eradal Ekici and Miguel Caldas, (2004), Slightly $\gamma$ continuous functions, Bol. Soc. Paran. Mat(3s), 22: 63-74.

Fao, G.L. (1987), on strongly $\alpha$-irresolute mappings, Indian J. Pure. Appl. Math. 18(1): 146-151.

Jain, R.C. The rule of regularly open sets in general topology, PhD Thesis, Meerut University, Institute of advance dstudies, Merut, India, 1980.
Levine, N. (1963), Semi-open sets and semicontinuity in topological spaces, Amer. Math. Monthly, 36-41.

Maki, H. R. Devi and K. Balachandran, (1993), Generalized- $\alpha$-closed sets in topology, Bull.Fukuoka Univ. Ed. Part III, 4213-21.

Mashhour, A.S. M.E. Abd El-Monsef and S.N. El-Deeb, (1983), On $\alpha$-continuous and $\alpha$-open mappings, Acta. Math. Hungaria, 41: 213-218.

Njastad, O. (1965), On some classes of nearly open sets, Pacif. J. Math., 15: 961-970.

Singal, A.R. and R.C. Jain, (1997), Slightly continuous mappings, J. indain. Math. Soc, 64195-203.

Stannum, R. (1974), The algebra of bounded continuous functions into a nonarchimedean field, acific, J. Math, 50169-185. 